\title{
Wearable Wireless Body Area Networks for Medical Applications
}

\author{
Carlos A. Tavera, ${ }^{1}$ Jesús H. Ortiz, ${ }^{2}$ Osamah I. Khalaf $\mathbb{D}^{1},{ }^{3}$ Diego F. Saavedra, ${ }^{1}$ \\ and Theyazn H. H. Aldhyani $\mathbb{D}^{4}$ \\ ${ }^{1}$ Universidad Santiago de Cali, Cali, Colombia \\ ${ }^{2}$ Closemobile ReD Telecommunications LS, Fuenlabrada, Spain \\ ${ }^{3}$ Al-Nahrain University, Bagdad, Iraq \\ ${ }^{4}$ Community College of Abqaiq, King Faisal University, P.O. Box 4000 Al-Ahsa, Saudi Arabia
}

Correspondence should be addressed to Osamah I. Khalaf; usama.ibrahem@coie-nahrain.edu.iq

Received 21 January 2021; Revised 21 February 2021; Accepted 10 April 2021; Published 26 April 2021

Academic Editor: Jude Hemanth

Copyright (c) 2021 Carlos A. Tavera et al. This is an open access article distributed under the Creative Commons Attribution License, which permits unrestricted use, distribution, and reproduction in any medium, provided the original work is properly cited.

\begin{abstract}
In recent times, there has been a significant growth in networks known as the wireless body area networks (WBANs). A WBAN connects distributed nodes throughout the human body, which can be placed on the skin, under the skin, or on clothing and can use the human body's electromagnetic waves. An approach to reduce the size of different telecommunication equipment is constantly being sought; this allows these devices to be closer to the body or even glued and embedded within the skin without making the user feel uncomfortable or posing as a danger for the user. These networks promise new medical applications; however, these are always based on the freedom of movement and the comfort they offer. Among the advantages of these networks is that they can significantly increase user's quality of life. For example, a person can carry a WBAN with built-in sensors that calculate the user's heart rate at any given time and send these data over the internet to user's doctor. This study provides a systematic review of WBAN, describing the applications and trends that have been developed with this type of network and, in addition, the protocols and standards that must be considered.
\end{abstract}

\section{Introduction}

A WBAN is a network built with different intelligent elements such as sensors, nodes, and actuators. This network is designed to work on the human body and its surroundings. The elements that conform the network must be highly reliable, exhibit low consumption, be operational at a high range (maximum $5 \mathrm{~m}$ ), must be resistant to interference, and must be able to operate within a wide range of transmission speeds [1]. These networks were first incepted in the 90s at Massachusetts Institute of Technology under the hypothesis of being able to attach electrical devices to the human body. Ever since, a high emphasis has been placed on increasing the bandwidth of the devices and consequently, decreasing their scope, consumption, and price. Figure 1 below provides a comparison between a WBAN network and other networks [2].
1.1. Regulations. The current IEEE 802.15.6 standard for WBAN technologies was published in 2012, and it is "a standard for short-range wireless communication devices" located near or within the human body (although it may not be limited to just human beings). WBAN technologies use existing industrial, scientific, and medical (ISM) bands, as well as the different frequency bands endorsed by local doctors or regulatory authorities [3]. This standard considers the effects on portable antennas owing to the presence of a human being (this varies depending on whether it is a man, a woman, whether they are tall, or thin), and the radiation patterns required to reduce specific absorption rates (SAR) in the body and changes from characteristic personal movements. Table 1 below shows the OSI model for a WBAN network [4].

Based on IEEE 802.15.6, the WBAN communication architecture is presented in Figure 2. 


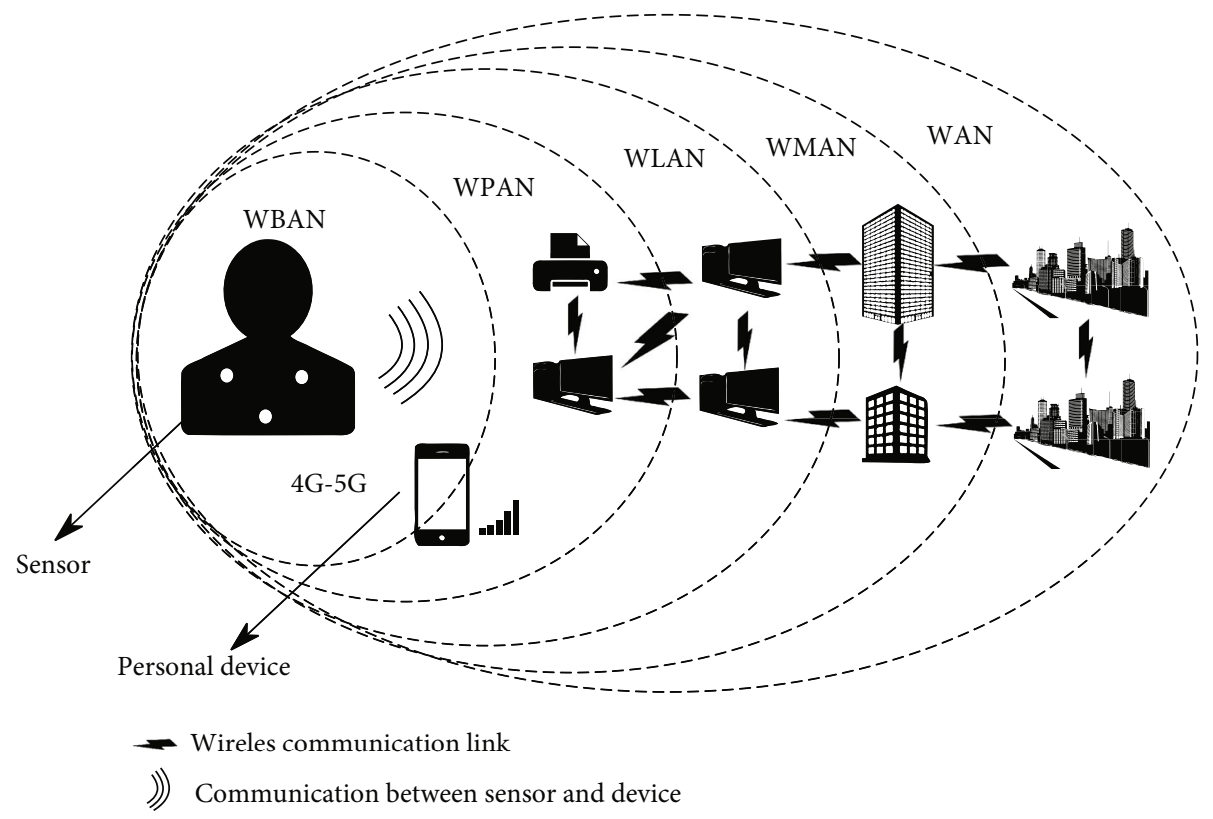

FIGURE 1: Comparison between WBAN and other networks.

TABLE 1: OSI model for a WBAN.

Media access control and security

\begin{tabular}{lll}
\hline Physical layer (PHY) narrow band (NB) & Ultrawide band (UWB) & Human body communications PHY (HBC) \\
\hline
\end{tabular}
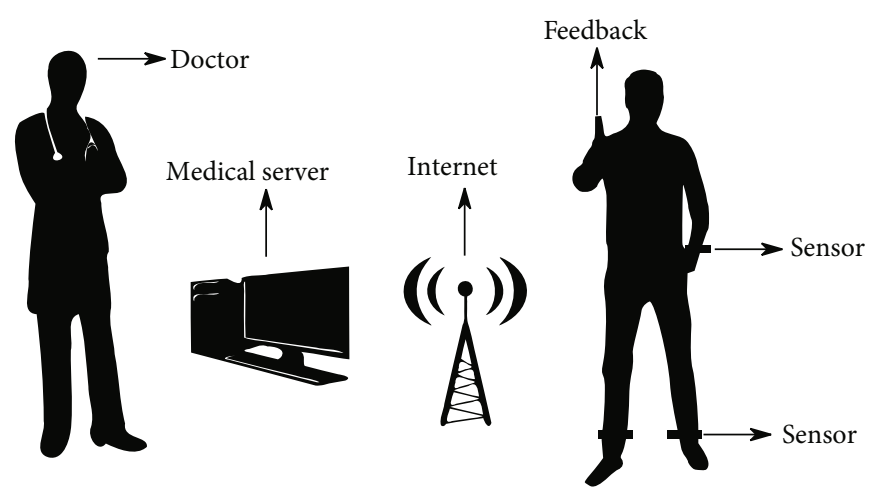

Figure 2: WBAN communication architecture.

Within the regulations, there are some requirements that must be considered, as presented below [5-7]:

(i) Nodes must be removed and inserted into the network in less than $3 \mathrm{~s}$

(ii) Each WBAN must support 256 nodes

(iii) Even if the person is constantly moving, the nodes must be able to provide stable and reliable communication

(iv) System latency should be less than $125 \mathrm{~ms}$ for medical applications and less than $250 \mathrm{~ms}$ for nonmedical applications. Their fluctuation must be less than $50 \mathrm{~ms}$ (v) WBANs on and within the body must be able to coexist within the same range. They must be supported on 10 randomly distributed WBANs and located in a physical layer in a $6 \mathrm{~m}^{3}$ cube

(vi) A WBAN can incorporate the UWB technology with narrow band transmission to cover different environments and support high data rates

(vii) They must also incorporate QoS management features to be self-correcting and secure and support priority services

(viii) WBANs must also include energy-saving systems that will allow them to operate in power-restricted environments 
(ix) WBAN links must support transfer rates in a range from $10 \mathrm{~Kb} / \mathrm{s}$ to $10 \mathrm{Mb} / \mathrm{s}$

(x) The packet error rate (PER) for a 256-octet payload must be less than $10 \%$ for most links that are based on the best PER performance [8-12]

(xi) All equipment must be capable of transmitting at $0.1 \mathrm{~mW}(-10 \mathrm{dBm})$. The maximum radiated transmit power must be less than $1 \mathrm{~mW}(0 \mathrm{dBm})$. This complies with the specific absorption rate (SAR) that the Federal Communications Commission has established, which is $1.6 \mathrm{~W} / \mathrm{Kg}$ per each $1 \mathrm{~g}$ of body tissue

(xii) They must be able to function in an environment where networks of different standards operate with each other to receive information

Table 2 below lists the frequency bands designated by the IEEE for WBAN $[13,14]$.

1.2. Applications. As applications can be categorized depending on the field in which the WBANs are involved, some applications range from military use to ubiquitous healthcare, training, sports, and entertainment. IEEE 802.15.6 has categorized applications of both medical and nonmedical nature. Table 3 below contains this distribution and provides evidence that the main characteristics of all WBAN applications are aimed at improving user quality of life.

Within the existing literature, different WBAN healthcare applications were found. Table 4 below describes some of these findings. The process implemented for searching, filtering, and selecting this information will be described in the methodology section.

1.3. WBAN Challenges. WBAN nodes are characterized by limited memory, processing, and power resources. Energy management is, as a matter of fact, considered an important challenge. As batteries are small and node power is limited, the energy consumption of the different devices needs to be reduced to secure a long battery life [30].

WBANs are important in the communication functionalities provided in medical applications and other application of smaller scope. Owing to their characteristics, some existing challenges and issues are discussed below.

Although WBANs allow a ubiquitous connection to the global network, they not only require support from the network infrastructure but also from different software implementations, such as remote procedures, database processing, and a user interface. Still, these implementations must feature low consumption and have little impact on the routing process [31].

Standards are still required for high-level data formats and which may also support using the user interface through social networks. The method and format used to deliver information outside the network are not usually implemented. Hence, the developer is responsible for the manner in which data are delivered to certain applications, implying that interoperability may be generated depending on the different solutions proposed $[32,33]$.
TABLE 2: Table 2 is reproduced from Movassaghi et al. [15], [under the Creative Commons Attribution License/public domain [15]].

\begin{tabular}{lcc}
\hline & Human body communication & \\
Frequency & & Bandwidth \\
$16 \mathrm{MHz}$ & $4 \mathrm{MHz}$ \\
$27 \mathrm{MHz}$ & $4 \mathrm{MHz}$ \\
& Narrowband communication & \\
Frequency & & Bandwidth \\
$402-405 \mathrm{MHz}$ & $300 \mathrm{KHz}$ \\
$420-450 \mathrm{MHz}$ & $300 \mathrm{KHz}$ \\
$863-870 \mathrm{MHz}$ & $400 \mathrm{KHz}$ \\
$902-928 \mathrm{MHz}$ & $500 \mathrm{KHz}$ \\
$956-956 \mathrm{MHz}$ & $400 \mathrm{KHz}$ \\
$2320-2400 \mathrm{MHz}$ & $1 \mathrm{MHz}$ \\
$2400-2438.5 \mathrm{MHz}$ & $1 \mathrm{MHz}$ \\
& \\
Frequency & UWB communication & Bandwidth \\
$3.2-4.7 \mathrm{GHZ}$ & $499 \mathrm{MHz}$ \\
$6.2-10.3 \mathrm{GHz}$ & & $499 \mathrm{MHz}$ \\
\hline
\end{tabular}

\section{Methods}

As part of the eligibility criteria, to conduct this systematic review, the following research question was taken into consideration: What are the different medical applications in which wearable WBAN technology is involved?

Bearing in mind this research question, the objective of this study was defined: to describe the different medical applications in which WBAN technology is involved.

Search sources: the bibliographic sources that were used to conduct this research are listed below:

(1) IEEE

(2) Springer

(3) ScienceDirect

Search: having selected the topic and the databases, the systematic search was conducted, implementing the different keywords and their respective logical connectors. The keywords used and the ideal combination of logical connectors for subsequent implementation in the databases are listed below:

(1) Sensor AND health AND WBAN

(2) Sensor AND health AND "wireless body area network"

(3) Sensor AND health AND (disease AND monitor AND microcontroller)

2.1. Selection. In this section, the different inclusion and exclusion criteria that were considered to filter the information are mentioned. 
TABLE 3: WBAN applications according to IEEE 802.15.6.

\begin{tabular}{lccc}
\hline & \multicolumn{2}{c}{ WBAN applications } \\
Wearable WBAN & Implantable WBAN & Remote control of medical devices & Nonmedical \\
\hline $\begin{array}{l}\text { Asthma. } \\
\begin{array}{l}\text { Portable health monitoring. } \\
\text { (cardiovascular diseases, } \\
\text { diabetes, and temperature). }\end{array}\end{array}$ & $\begin{array}{c}\text { Cancer screening. } \\
\text { Cardiovascular diseases (CD). }\end{array}$ & $\begin{array}{c}\text { Telemedicine systems. } \\
\text { Security to uniformed personnel. }\end{array}$ & $\begin{array}{c}\text { Entertainment applications. } \\
\text { Emergencies (nonmedical). }\end{array}$ \\
\hline
\end{tabular}

TABLE 4: Different WBAN applications.

\begin{tabular}{|c|c|c|c|c|}
\hline Reference & Aplicación & Contribution & $\begin{array}{l}\text { Wearable } \\
\text { WBAN }\end{array}$ & $\begin{array}{l}\text { Medical } \\
\text { Remote control } \\
\text { of medical devices }\end{array}$ \\
\hline$[16]$ & $\begin{array}{l}\text { It uses Bluetooth communication to measure } \\
\text { body temperature, heartbeats, and possible falls. }\end{array}$ & It implements power by solar energy. & $\mathrm{x}$ & \\
\hline$[17]$ & $\begin{array}{l}\text { It uses a GSM module to send heartbeat } \\
\text { and body temperature information. }\end{array}$ & Optical sensor. & & $\mathrm{x}$ \\
\hline [18] & $\begin{array}{l}\text { Maintains constant measurement of } \\
\text { different medical patient parameters. }\end{array}$ & $\begin{array}{c}\text { System with first aid assistance } \\
\text { instructions. }\end{array}$ & & $\mathrm{x}$ \\
\hline [19] & $\begin{array}{l}\text { It uses an ARM7 to determine the patient's } \\
\text { heart condition. }\end{array}$ & $\begin{array}{l}\text { Uses the android platform to communicate } \\
\text { the system with the doctor. }\end{array}$ & & $\mathrm{x}$ \\
\hline$[20]$ & $\begin{array}{l}\text { It measures the person's heart rate, blood pressure, } \\
\text { temperature, and breathing. }\end{array}$ & $\begin{array}{l}\text { It uses a GSM modem to send the } \\
\text { information to the doctor. }\end{array}$ & & $\mathrm{x}$ \\
\hline [21] & $\begin{array}{l}\text { Assesses patient vibrations to determine whether } \\
\text { the patient suffers from Parkinson's disease (PD). }\end{array}$ & $\begin{array}{l}\text { The system makes it possible to determine } \\
\text { the evolution of the disease. }\end{array}$ & $\mathrm{x}$ & \\
\hline$[22]$ & $\begin{array}{l}\text { It uses sensors on the cellular phone to analyze } \\
\text { the patient's gait and determine if the patient } \\
\text { suffers from PD. }\end{array}$ & $\begin{array}{l}\text { Implement a smartphone, database, } \\
\text { and web application. }\end{array}$ & & $\mathrm{x}$ \\
\hline$[23]$ & $\begin{array}{l}\text { It measures the kinematics of the patient's } \\
\text { gait to determine if they have PD. }\end{array}$ & $\begin{array}{l}\text { Implement sensors in the lower limbs } \\
\text { and upper body. }\end{array}$ & $\mathrm{x}$ & \\
\hline [24] & $\begin{array}{l}\text { Sensors placed on the soles of the feet to determine } \\
\text { whether the patient suffers from PD. }\end{array}$ & $\begin{array}{l}\text { Mobile application was implemented } \\
\text { to monitor the patient. }\end{array}$ & $\mathrm{x}$ & \\
\hline$[17]$ & $\begin{array}{l}\text { Sensors in the lower body to determine whether } \\
\text { the patient suffers from PD. }\end{array}$ & It uses ZigBee technology and protocols. & $\mathrm{x}$ & \\
\hline [25] & $\begin{array}{l}\text { Implementation of inertial sensors to determine } \\
\text { whether the patient suffers from multiple sclerosis. }\end{array}$ & - & $\mathrm{x}$ & \\
\hline [26] & EEG sensor for assessing different brain activities. & $\begin{array}{l}\text { Uses ensemble classifier for epileptic } \\
\text { seizure detection for imperfect EEG data. }\end{array}$ & $\mathrm{x}$ & \\
\hline$[27]$ & System for real-time detection of epilepsies. & $\begin{array}{l}\text { The sensor medium access control } \\
\text { (SMAC) protocol is used to reduce delays } \\
\text { in the time for sending information. }\end{array}$ & & $\mathrm{x}$ \\
\hline [28] & Clock sensor for detecting epilepsies in real time. & - & & $\mathrm{x}$ \\
\hline$[29]$ & Clock sensor for monitoring seizures in real time. & $\begin{array}{l}\text { Implement communication through } \\
\text { the cloud. }\end{array}$ & & $\mathrm{x}$ \\
\hline
\end{tabular}

Implantable WBANs and nonmedical applications were not considered.

Inclusion criteria: the articles that should mainly be on the selected list are those that meet the following characteristics:

(1) They must be in Spanish, English, or Portuguese

(2) Articles must have publication dates no older than five years (2015-2020).

(3) These must be downloadable articles
TABLE 5: Summary of filtered articles.

\begin{tabular}{lccccc}
\hline & Keywords & $\begin{array}{c}\text { Year and } \\
\text { type filter }\end{array}$ & Title & Abstract & Chosen \\
\hline IEEE & 750 & 572 & 84 & 76 & 18 \\
Springer & 2,415 & 678 & 51 & 40 & 10 \\
ScienceDirect & 1,107 & 900 & 34 & 10 & 6 \\
& & & & Total & 34 \\
\hline
\end{tabular}




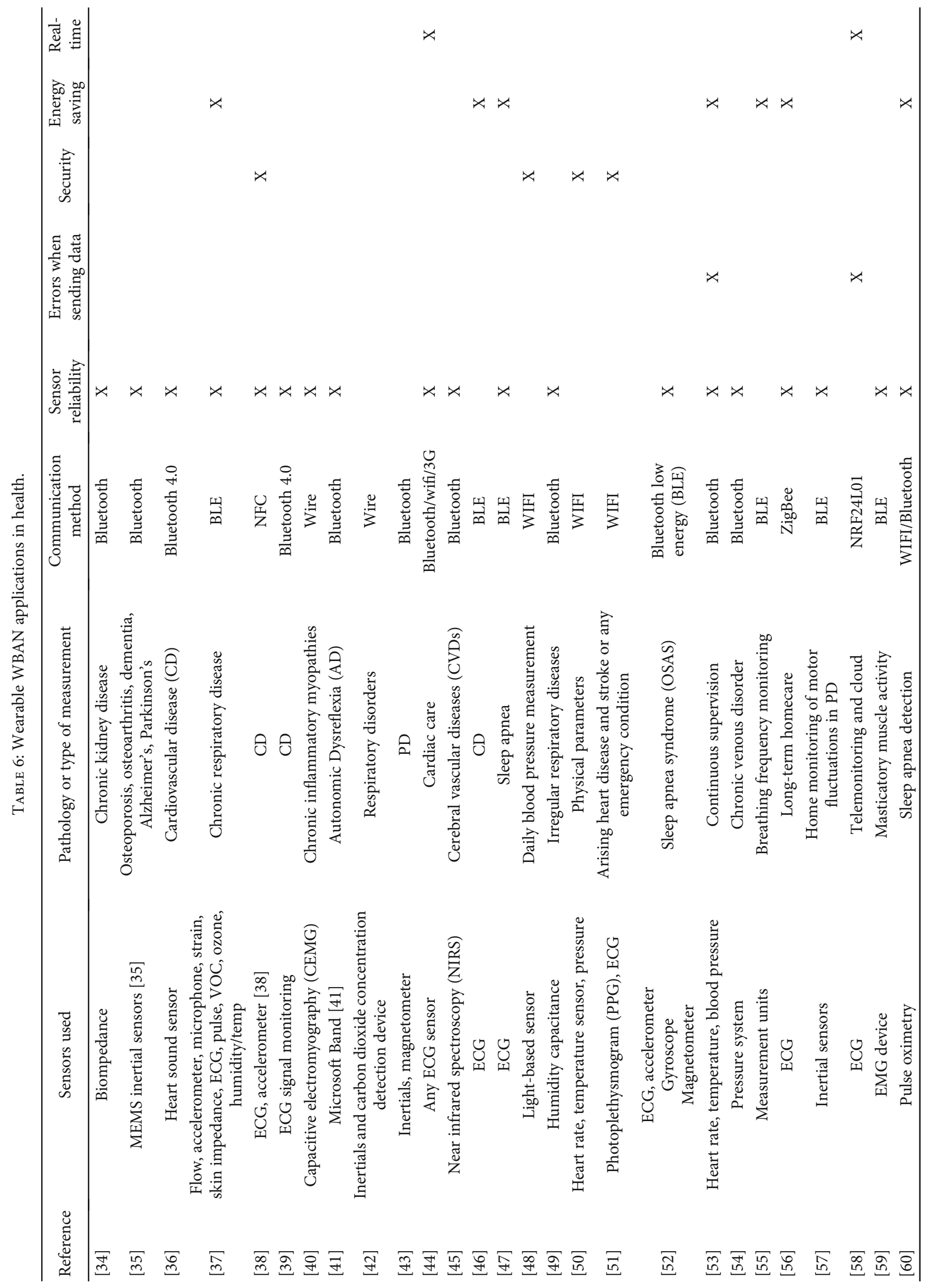


TABLE 7: WBAN trends.

\begin{tabular}{|c|c|c|c|}
\hline Reference & Application & Novelty & Sensors \\
\hline [61] & Long-term continuous medical monitoring & $\begin{array}{l}\text { Autonomous system, by means of } \\
\text { solar energy }\end{array}$ & Inertials, temperature, and pulse \\
\hline [62] & $\mathrm{PD}$ & Holistic system & $\begin{array}{l}\text { Microsoft band, speech analysis, } \\
\text { finger tapping }\end{array}$ \\
\hline [63] & Classification of physical activity & $\begin{array}{l}\text { Classification method using } \\
\text { smartphones }\end{array}$ & Inertial \\
\hline [64] & Peripheral artery disease & $\begin{array}{c}\text { Passive wearable skin patch sensor } \\
\text { measures }\end{array}$ & Electromagnetic resonant sensor \\
\hline [65] & $\begin{array}{c}\text { Detection of abnormalities, as well as intrusions, } \\
\text { such as forgery, insertions, and modifications } \\
\text { in the ECG data }\end{array}$ & Identify anomalies in ECG signals & Dataset \\
\hline [66] & Proposal for emergency classification transmission & Priority data transmission & $\begin{array}{l}\text { Oxygen in blood, pulse, and } \\
\text { position measurements }\end{array}$ \\
\hline [67] & Stroke, PD, and epilepsy & $\begin{array}{l}\text { Garment with integrated sensors, user } \\
\text { needs such as design and comfort are } \\
\text { identified }\end{array}$ & $\begin{array}{l}\text { Accelerometer, gyroscope, } \\
\text { and ECG }\end{array}$ \\
\hline
\end{tabular}

(4) The main topic addressed by the authors must be linked to the wearable WBAN networks and their different implementations

(5) The applications described by the authors must be oriented toward medical use in patients with different pathologies follows:

Exclusion criteria: articles whose information are as

(1) Is not considered accurate or the author has not solved the research problem

(2) The applications in which the WBAN is involved are not medical, but this technology is used as hobbies, laboratory practices, or to measure information that is not related to health

Bearing in mind this methodology, we started the exploration process, which lasted 31 days, and engaged the participation from three engineers. One of them is currently pursuing a Master's of computer science, and two of them hold $\mathrm{PhDs}$ in engineering. This consolidates the experience of the researchers to conduct the said research, with an odd number of researchers, for the correct choice of articles. Table 5 shows the result of the different filters applied in the review.

As a result, Table 6 presents the wearable applications involving WBANs in health, the sensors used, and the characteristics considered by the authors.

In later sections, the results obtained from this exploration are presented.

\section{Results and Discussions}

From Table 7, a trend inclining toward the use of communication devices such as low-energy Bluetooth and WIFI can be observed owing to their great standardization and ability to connect to a mobile hub, such as those available in most smartphones. This can be attributed to the fact that most of the applications found used a hub, such as those available in most smartphones, because it allows the information to be directly loaded to a cloud service if necessary.

In addition, at the research level, there is a tendency to better guarantee the reliability of the data obtained through the sensors, as well as improving the consumption of the devices developed using techniques for energy saving, power generation, or even dedicated FPGA chips. Conversely, aspects such as security, communication reliability, and real time are less approached, and on the contrary, more challenges are generated for existing protocols for improvement or new models are constantly being proposed. It was found that $66 \%$ of WBAN wearable applications used Bluetooth, $17 \%$ WIFI, and only 3.5\% ZigBee or NFC. The most common problems noted were heart problems and respiratory disorders.

Real-time applications were less widely used, commonly using protocols such as ZigBee. They have the disadvantage that they are limited to a local environment because switching to an internet protocol increases their latency. However, although wearable WBAN applications do not commonly use real time, information processing is performed through artificial intelligence to diagnose risk conditions and generate early medical alerts.

Bioimpedance and capacitance analysis were used as support in the diagnosis and monitoring of different pathologies because they analyze the body sections composition, evaluating in a general way the hydration status, lean, and fat mass. Even so, there are other applications that also involve this technique, for example, to make 3D images of internal organs to track diabetic patients. Conversely, inertial and ECG sensors were the most used in the different systems, being deemed as user-friendly sensors owing to their many user modules.

It is expected that with the development of new technological products such as smart watches and wireless 
headphones, which currently have a great impact on society, they will continue to improve the hardware related directly to the technologies used for WBAN. These devices have encouraged the improvement of technologies such as Bluetooth (Bluetooth 5.2) and low-power processors, improving the ability to connect to multiple nodes, reducing energy consumption, and ability to preprocess sensor data according to medical models, helping to guarantee the security and reliability of communications, as well as the improvement of transmission speeds, and in addition, to achieve future applications in real-time outside a local environment, through the development of technologies such as $5 \mathrm{G}$ and tactile internet.

\section{Conclusion}

WBAN technology is increasingly being used in applications where people and their well-being are involved, increasing the presence of technologies in patients' health. WBAN devices not only provide constant information about patients and their pathology but can also diagnose diseases and facilitate treatments and constant medical involvement.

It is important to continue advancing in the continuous reliability improvement of the information obtained using the WBAN, as well as device autonomy. This will allow the creation of new robust models, through techniques such as artificial intelligence that can provide permanent diagnosis and monitoring for diseases affecting a large part of the population, while taking advantage of the constant improvement of technologies such as tactile internet and personal gadgets.

\section{Data Availability}

The data is available in https://www.gambitcomm.com/site/ gambit4.shtml?gclid=Cj0KCQiAx9mABhD0ARIsAEfpav THRH-mpys3ZJQbOuSmjUcvhz-wV5kl4-216-t5WQwF2D acULvftCgaAvXqEALw_wcB.

\section{Disclosure}

The Faculty of Engineering did not have a role in the conduct of the study, in the collection, management, analysis, interpretation of data, or in the preparation of the manuscript.

\section{Conflicts of Interest}

The author(s) declared no potential conflicts of interest with respect to the research, authorship, and/or publication of this article.

\section{Authors' Contributions}

The views expressed in this article are those of the authors and do not necessarily represent the views of the Faculty of Engineering of the Universidad Santiago de Cali.

\section{Acknowledgments}

This research has been funded by Dirección General de Investigaciones of Universidad Santiago de Cali under call No. 01-2021.

\section{References}

[1] S. Bernedo, Caracterización Experimental Del Canal De La Red Wban, UAM_Biblioteca, 2016.

[2] R. Negra, I. Jemili, and A. Belghith, "Wireless body area networks: applications and technologies," Procedia Computer Science, vol. 83, pp. 1274-1281, 2016.

[3] K. Suriyakrishnaan and D. Sridharan, "Critical data delivery using TOPSIS in wireless body area networks," Circuits and Systems, vol. 7, no. 6, pp. 622-629, 2016.

[4] H. Kaschel, J. Alvarado, and V. Torres, Redes de Area Corporal Inalámbricos : Requisitos, Desafíos e Interferencias, XV Congreso Internacional De Telecomunicaciones Senacitel, 2014.

[5] K. A. Ogudo, D. M. J. Nestor, O. I. Khalaf, and H. D. Kasmaei, "A device performance and data analytics concept for smartphones' IoT services and machine-type communication in cellular networks," Symmetry, vol. 11, no. 4, p. 593, 2019.

[6] I. Al-Barazanchi, A. S. Shibghatullah, and S. R. Selamat, "A new routing protocols for reducing path loss in wireless body area network (WBAN)," Journal of Telecommunication, Electronic and Computer Engineering (JTEC), vol. 9, no. 1-2, pp. 93-97, 2017.

[7] F. Ullah, A. H. Abdullah, M. Q. Jan, and K. N. Qureshi, "Patient data prioritization in the cross-layer designs of wireless body area network," Journal of Computer Networks and Communications, vol. 2015, Article ID 516838, 21 pages, 2015.

[8] T. X. Tran, X. P. Nguyen, D. N. Nguyen et al., "Effect of polyalkylene-glycol quenchant on the distortion, hardness, and microstructure of 65Mn steel," Computers, Materials \& Continua, vol. 67, no. 3, pp. 3249-3264, 2021.

[9] C. A. T. Romero, J. H. Ortiz, O. I. Khalaf, and A. R. Prado, "Web application commercial design for financial entities based on business intelligence," Computers, Materials \& Continua, vol. 67, no. 3, pp. 3177-3188, 2021.

[10] M. J. Awan, M. S. M. Rahim, H. Nobanee, A. Yasin, O. I. Khalaf, and U. Ishfaq, "A big data approach to black friday sales," Intelligent Automation and Soft Computing, vol. 27, no. 3, pp. 785-797, 2021.

[11] F. W. Alsaade, T. H. H. Aldhyani, and M. H. Al-Adhaileh, "Developing a recognition system for classifying covid-19 using a convolutional neural network algorithm," Computers, Materials \& Continua, vol. 680, no. 1, pp. 805-819, 2021.

[12] M. Krichen, S. Mechti, R. Alroobaea et al., "A formal testing model for operating room control system using internet of things," Computers, Materials \& Continua, vol. 66, no. 3, pp. 2997-3011, 2021.

[13] J. Steward, Northumbria research link, vol. 24, NrlNorthumbriaAcUk, 2011.

[14] M. Ghamari, B. Janko, R. S. Sherratt, W. Harwin, R. Piechockic, and C. Soltanpur, "A survey on wireless body area networks for ehealthcare systems in residential environments," Sensors, vol. 16, no. 6, pp. 831-833, 2016.

[15] S. Movassaghi, M. Abolhasan, J. Lipman, D. Smith, and A. Jamalipour, "Wireless nody area networks: a survey," IEEE Communications Surveys \& Tutorials, vol. 16, no. 3, pp. 16581686, 2014.

[16] T. Wu, F. Wu, J. M. Redoute, and M. R. Yuce, "An autonomous wireless body area network implementation towards IoT connected healthcare applications," IEEE Access, vol. 5, pp. 11413-11422, 2017. 
[17] M. W. Alam, T. Sultana, and M. S. Alam, "A heartbeat and temperature measuring system for remote health monitoring using wireless body area network," International Journal of BioScience and Bio-Technology, vol. 8, no. 1, pp. 171-190, 2016.

[18] P. Mohnani and F. Jabeen, "Modeling and optimizing wireless body area network data using PSO in virtual doctor server," Communications on Applied Electronics, vol. 4, no. 2, pp. 3943, 2016.

[19] N. Sulaiman, G. Abdulsahib, O. Khalaf, and M. N. Mohammed, "Effect of using different propagations of OLSR and DSDV routing protocols," in Proceedings of the IEEE International Conference on Intelligent Systems Structureing and Simulation, pp. 540-545, Langkawi, Malaysia, 2014.

[20] O. I. Khalaf and G. M. Abdulsahib, "Frequency estimation by the method of minimum mean squared error and P-value distributed in the wireless sensor network," Journal of Information Science and Engineering, vol. 35, no. 5, pp. 1099-1112, 2019.

[21] R. Contreras, M. Huerta, G. Sagbay et al., "Tremors quantification in Parkinson patients using smartwatches," in 2016 IEEE Ecuador Tech Chapters Meet ETCM 2016, Guayaquil, Ecuador, 2016.

[22] O. I. Khalaf, G. M. Abdulsahib, and M. Sadik, "A modified algorithm for improving lifetime WSN," Journal of Engineering and Applied Sciences, vol. 13, pp. 9277-9282, 2018.

[23] Z. Dong, H. Gu, Y. Wan, W. Zhuang, R. Rojas-Cessa, and E. Rabin, "Wireless body area sensor network for posture and gait monitoring of individuals with Parkinson's disease," in ICNSC 2015-2015 IEEE 12th Int Conf Networking, Sens Control, pp. 81-86, Taipei, Taiwan, 2015.

[24] G. M. Abdulsahib and O. I. Khalaf, "Comparison and evaluation of cloud processing models in cloud-based networks," International Journal of Simulation: Systems, Science \& Technology, vol. 19, no. 5, 2018.

[25] J. Gong, M. M. Engelhard, M. D. Goldman, and J. Lach, "Correlations between inertial body sensor measures and clinical measures in multiple sclerosis," in Proceedings of the 10th EAI International Conference on Body Area Networks, Sydney New South Wales Australia, 2015.

[26] K. Abualsaud, M. Mahmuddin, M. Saleh, and A. Mohamed, "Ensemble classifier for epileptic seizure detection for imperfect EEG data," Scientific World Journal, vol. 2015, article 945689, 15 pages, 2015.

[27] S. Otoum, M. Ahmed, and H. T. Mouftah, "Sensor medium access control (SMAC)-based epilepsy patients monitoring system," in 2015 IEEE 28th Canadian Conference on Electrical and Computer Engineering (CCECE), pp. 1109-1114, Halifax, NS, Canada, 2015.

[28] P. M. Vergara, E. De La Cal, J. R. Villar, V. M. González, and J. Sedano, "An IoT platform for epilepsy monitoring and supervising," Journal of Sensors, vol. 2017, Article ID 6043069, 18 pages, 2017.

[29] A. F. Subahi, Y. Alotaibi, O. I. Khalaf, and F. Ajesh, "Packet drop battling mechanism for energy aware detection in wireless networks," Computers, Materials \& Continua, vol. 66, no. 2, pp. 2077-2086, 2020.

[30] M. Vallejo, Diseño y Validación de Políticas de Transmisión de Datos en Redes inalámbricas de Sensores de Bajo Consumo, Tesis Dr., 2016.

[31] S. Al-Janabi, I. Al-Shourbaji, M. Shojafar, and S. Shamshirband, "Survey of main challenges (security and privacy) in wireless body area networks for healthcare applications," Egyptian Informatics Journal, vol. 18, no. 2, pp. 113122, 2017.

[32] G. M. Abdulsahib and O. I. Khalaf, "An improved algorithm to fire detection in forest by using wireless sensor networks," International Journal of Civil Engineering \& Technology (IJCIET)-Scopus Indexed, vol. 9, no. 11, pp. 369-377, 2018.

[33] O. Wisesa, A. Adriansyah, and O. I. Khalaf, "Prediction analysis sales for corporate services telecommunications company using gradient boost algorithm," in 2020 2nd International Conference on Broadband Communications, Wireless Sensors and Powering (BCWSP), pp. 101-106, Yogyakarta, Indonesia, 2020.

[34] J. Ferreira, I. Pau, K. Lindecrantz, and F. Seoane, "A handheld and textile-enabled bioimpedance system for ubiquitous body composition analysis. An initial functional validation," IEEE Journal of Biomedical and Health Informatics, vol. 21, no. 5, pp. 1224-1232, 2017.

[35] S. Majumder, T. Mondal, and M. J. Deen, “A simple, low-cost and efficient gait analyzer for wearable healthcare applications," IEEE Sensors Journal, vol. 19, no. 6, pp. 2320-2329, 2019.

[36] O. I. Khalaf and B. M. Sabbar, "An overview on wireless sensor networks and finding optimal location of nodes," Periodicals of Engineering and Natural Sciences (PEN), vol. 7, no. 3, pp. 1096-1101, 2019.

[37] X. Xiang, Q. Li, S. Khan, and O. I. Khalaf, "Urban water resource management for sustainable environment planning using artificial intelligence techniques," Environmental Impact Assessment Review, vol. 86, p. 106515, 2021.

[38] S. Izumi, K. Yamashita, M. Nakano et al., "A wearable healthcare system with a 13.7 \$ $\mu$ A noise tolerant ECG processor," IEEE Transactions on Biomedical Circuits and Systems, vol. 9, no. 5, pp. 733-742, 2015.

[39] C. Wang, Y. Qin, H. Jin et al., "A low power cardiovascular healthcare system with cross-layer optimization from sensing patch to cloud platform," IEEE Transactions on Biomedical Circuits and Systems, vol. 13, no. 2, pp. 314-329, 2019.

[40] C. L. Ng, M. B. I. Reaz, and M. E. H. Chowdhury, “A low noise capacitive electromyography monitoring system for remote healthcare applications," IEEE Sensors Journal, vol. 20, no. 6, pp. 3333-3342, 2020.

[41] S. Suresh and B. S. Duerstock, "Automated detection of symptomatic autonomic dysreflexia through multimodal sensing," IEEE Journal of Translational Engineering in Health and Medicine, vol. 8, pp. 1-8, 2020.

[42] G. Dan, J. Zhao, Z. Chen, H. Yang, and Z. Zhu, "A novel signal acquisition system for wearable respiratory monitoring," IEEE Access, vol. 6, pp. 34365-34371, 2018.

[43] P. Pierleoni, A. Belli, O. Bazgir, L. Maurizi, M. Paniccia, and L. Palma, "A smart inertial system for $24 \mathrm{~h}$ monitoring and classification of tremor and freezing of gait in Parkinson's disease," IEEE Sensors Journal, vol. 19, no. 23, pp. 11612-11623, 2019.

[44] A. Bansal, S. Kumar, A. Bajpai et al., "Remote health monitoring system for detecting cardiac disorders," IET Systems Biology, vol. 9, no. 6, pp. 309-314, 2015.

[45] Q. Zhang, N. Zhang, L. Kang et al., “Technology development for simultaneous wearable monitoring of cerebral hemodynamics and blood pressure," IEEE Journal of Biomedical and Health Informatics, vol. 23, no. 5, pp. 1952-1963, 2019. 
[46] C. Beach, S. Krachunov, J. Pope et al., “An ultra low power personalizable wrist worn ECG monitor integrated with IoT infrastructure," IEEE Access, vol. 6, pp. 44010-44021, 2018.

[47] O. I. Khalaf and G. M. Abdulsahib, "Energy efficient routing and reliable data transmission protocol in WSN," International Journal of Advances in Soft Computing and its Application, vol. 12, no. 3, pp. 45-53, 2020.

[48] A. D. Salman, O. I. Khalaf, and G. M. Abdulsahib, "An adaptive intelligent alarm system for wireless sensor network," Indonesian Journal of Electrical Engineering and Computer Science, vol. 15, no. 1, pp. 142-147, 2019.

[49] B. Li, Q. Tian, H. Su, X. Wang, T. Wang, and D. Zhang, "High sensitivity portable capacitive humidity sensor based on $\operatorname{In}_{2} \mathrm{O}_{3}$ nanocubes-decorated GO nanosheets and its wearable application in respiration detection," Sensors and Actuators B: Chemical, vol. 299, article 126973, 2019.

[50] M. Pravin Savaridass, N. Ikram, R. Deepika, and R. Aarnika, "Development of smart health monitoring system using Internet of Things," Materials Today: Proceedings, vol. 26, 2020.

[51] O. I. Khalaf, G. M. Abdulsahib, H. D. Kasmaei, and K. A. Ogudo, "A new algorithm on application of blockchain technology in live stream video transmissions and telecommunications," International Journal of e-Collaboration, vol. 16, no. 1, pp. 16-32, 2020.

[52] J. E. Hernandez and E. Cretu, "A wireless, real-time respiratory effort and body position monitoring system for sleep," Biomedical Signal Processing and Control, vol. 61, article 102023, 2020.

[53] S. K. Prasad, J. Rachna, O. I. Khalaf, and D.-N. Le, "Map matching algorithm: real time location tracking for smart security application," Telecommunications and Radio Engineering, vol. 79, no. 13, pp. 1189-1203, 2020.

[54] R. Li, B. Nie, C. Zhai et al., "Telemedical wearable sensing platform for management of chronic venous disorder," Annals of Biomedical Engineering, vol. 44, no. 7, pp. 22822291, 2016.

[55] A. Cesareo, E. Biffi, D. Cuesta-Frau, M. G. D’Angelo, and A. Aliverti, "A novel acquisition platform for long-term breathing frequency monitoring based on inertial measurement units," Medical \& Biological Engineering \& Computing, vol. 58, no. 4, pp. 785-804, 2020.

[56] Y. Wang, S. Doleschel, R. Wunderlich, and S. Heinen, "A wearable wireless ECG monitoring system with dynamic transmission power control for long-term homecare," Journal of Medical Systems, vol. 39, no. 3, p. 35, 2015.

[57] L. Borzì, M. Varrecchia, G. Olmo et al., "Home monitoring of motor fluctuations in Parkinson's disease patients," Journal of Reliable Intelligent Environments, vol. 5, no. 3, pp. 145-162, 2019.

[58] A. El Attaoui, M. Hazmi, A. Jilbab, and A. Bourouhou, "Wearable wireless sensors network for ECG telemonitoring using neural network for features extraction," Wireless Personal Communications, vol. 111, no. 3, pp. 1955-1976, 2020.

[59] S. Prasad, M. Paulin, R. D. Cannon, S. Palla, and M. Farella, "Smartphone-assisted monitoring of masticatory muscle activity in freely moving individuals," Clinical Oral Investigations, vol. 23, no. 9, pp. 3601-3611, 2019.

[60] F. Mendonça, S. S. Mostafa, F. Morgado-Dias, J. L. NavarroMesa, G. Juliá-Serdá, and A. G. Ravelo-García, "A portable wireless device based on oximetry for sleep apnea detection," Computing, vol. 100, no. 11, pp. 1203-1219, 2018.
[61] T. H. H. Aldhyani, M. Alrasheed, M. H. Al-Adaileh, A. A. Alqarni, M. Y. Alzahrani, and A. H. Alahmadi, "Deep learning and holt-trend algorithms for predicting covid-19 pandemic," Computers, Materials \& Continua, vol. 67, no. 2, pp. 21412160, 2017.

[62] K. M. Tsiouris, D. Gatsios, G. Rigas et al., "PD_Manager: an mHealth platform for Parkinson's disease patient management," Healthcare Technology Letters, vol. 4, no. 3, pp. 102 108, 2017

[63] P. Li, Y. Wang, Y. Tian, T. Zhou, and J. Li, "An automatic useradapted physical activity classification method using smartphones," IEEE Transactions on Biomedical Engineering, vol. 64, no. 3, pp. 1-714, 2016.

[64] K. Cluff, J. Patterson, R. Becker et al., "Passive wearable skin patch sensor measures limb hemodynamics based on electromagnetic resonance," IEEE Transactions on Biomedical Engineering, vol. 65, no. 4, pp. 847-856, 2018.

[65] O. I. Khalaf, F. Ajesh, A. A. Hamad, G. N. Nguyen, and D. N. Le, "Efficient dual-cooperative bait detection scheme for collaborative attackers on mobile ad-hoc networks," IEEE Access, vol. 8, pp. 227962-227969, 2020.

[66] A. A. Hamad, A. S. Al-Obeidi, E. H. Al-Taiy, O. I. Khalaf, and D. Le, "Synchronization phenomena investigation of a new nonlinear dynamical system $4 \mathrm{~d}$ by gardano's and lyapunov's methods," Computers, Materials \& Continua, vol. 66, no. 3, pp. 3311-3327, 2021.

[67] O. I. Khalaf, G. M. Abdulsahib, and B. M. Sabbar, "Optimization of wireless sensor network coverage using the bee algorithm," Journal of Information Science and Engineering, vol. 36, no. 2, pp. 377-386, 2020. 